\title{
Manuel Vázquez Montalbán, ¿poeta novísimo?
}

\author{
SERGIO GARCÍA GARCÍA
}

"Un fantasma recorre la poesía española. Para unos, el fantasma es un libro: Nueve novísimos. Para otros, el fantasma es el cerco de desprecio o de ira que ese mismo libro soliviante en muchos de sus abundantes lectores." Con esta paráfrasis del inicio del Manifiesto comunista el poeta Félix Grande (283), en una de las críticas más recurrentes hacia la antología Nueve novísimos poetas españoles, realizada por Josep Maria Castellet en 1970, planteaba los dos posibles orígenes de la fuerte repercusión que dicha antología produjo en el panorama poético español del tardofranquismo: la propuesta castelletiana en sí misma o la polémica que se originó tras su publicación. A pesar de ser dos los caminos por los cuales este fantasma se iba cerniendo sobre la España de 1971 -año de publicación del texto de Grande-, que con el paso del tiempo acabarían por ser uno solo, en aquel momento un hecho estaba claro: Nueve novísimos poetas españoles paulatinamente se estaba consolidando como el canon de la llamada Generación del 68 (Lanz 15), a la que también se le apodó como Generación del 70, más atenta esta etiqueta a la antología de Castellet que a la poesía anterior (21).

Se conoce como Generación del 68 a una serie de poetas que, inicialmente, publicó sus primeras obras entre 1966 y 1968, aunque la nómina fue ampliándose hasta mediados de los años setenta ${ }^{1}$, y que no vivió la guerra civil, es decir, estos poetas alcanzaron "la mayoría de edad en los años sesenta, cuando el mundo ha cambiado profundamente" (Bou y Pittarello 17). Sus nombres comienzan a ser constantes en tres antologías claves para la época: Antología de la joven poesía española [1967], de Enrique Martín Pardo, y Doce jóvenes poetas españoles [1967] y Antología de la nueva poesía española [1968], ambas de José Batlló. Es en esta última, como establece Juan José Lanz, "donde por primera vez se teoriza acerca de uno de los elementos fundamentales en la construcción teórico-estética de Nueve novísimos: la ruptura estética con la poesía anterior", "el 'grito de guerra' — continúa Lanz-, bajo los $-$

1 Véase Prieto de Paula 41. 
ecos revolucionarios del Mayo francés, de la joven poesía española que entonces empezaba a surgir" (116 y 117) ${ }^{2}$. Al margen de esta nueva ruptura, de la que Castellet se hará su adalid, Ángel Luis Prieto de Paula expone las dos ideas principales que caracterizaron a estas antologías, así como a las que se publicaron posteriormente: el intento de crear una homogeneidad interna ante "la dispersión de títulos y corrientes que [...] constituían la última poesía española" de aquellos años, y la incitación "a los jóvenes de la misma generación, "descolgados" u obedientes a fórmulas propias, a que orientaran su obra según los nuevos requerimientos estéticos" (78). Desde una mirada generalizada, los requerimientos o las nuevas actitudes estéticas de los poetas sesentayochistas podrían resumirse en cuatro puntos:

1) el interés por los mitos provenientes de los medios de comunicación de masas, a partir de los cuales "se estaba incubando el escepticismo sobre cualquier modo de fe totalizadora" (111), y por una también, aunque en menor medida, "literatura de masas", como la novela policíaca (Bou y Pittarello 18),

2) lo cual traerá consigo un notable rechazo de la tradición poética española inmediatamente anterior, y hará que estos autores vinculen sus trayectorias a las de los poetas de la Generación del 27, "por el hecho de que esta generación dominante en la anteguerra y arrinconada por las circunstancias postbélicas fue considerada como un tramo perdido del que hubiera debido ser el camino normal de la poesía española del siglo XX" (Prieto de Paula 147 y 148);

3) los poetas del 68 , entonces, establecerán un antes y un después con respecto a la poesía del medio siglo, remarcado por la importante presencia en sus textos del imaginario cultural de su época, como se ya mencionado en el primer punto, muy vinculado con una "cultura juvenil”, según Enric Bou y Elide Pittarello, que en los sesenta se proclamó como "la cultura dominante en el mundo occidental, a causa de factores como la masa concentrada en el poder adquisitivo, el hecho de que cada $-$

2 El preciso señalar también como elemento diferenciador entre la poesía del 68 y la que años antes se escribió en España la creación en 1964 de la colección de poesía El Bardo por José Batlló. Las preferencias de estos jóvenes autores ya no estaban orientadas hacia Madrid y su colección Adonáis, sino hacia Barcelona, donde no solo El Bardo iba ampliando su nómina de escritores, sino también la colección Ocnos, creada por Joaquín Marco (Prieto de Paula 137). 
nueva generación de adultos había pasado por la experiencia de la cultura juvenil con experiencia propia y estaba marcada por esta experiencia", así como con "la prodigiosa velocidad del cambio tecnológico" y con "la 'asombrosa internacionalización' por el auge de la industria cinematográfica norteamericana en el periodo de entreguerras" (Hollywood, sobre todo) (15) -estos poetas, asegura Antonio García Berrio, "fueron obviamente hijos de sus circunstancias" (13), sentencia que podría perfectamente complementar el inicio las conclusiones que expuso Castellet en Nueve novísimos: "no hay otra actitud posible para la comprensión de la sensiblidad de la nueva generación que intentar establecer un código de sus mitologías" (45);

4) ruptura también con la poesía anterior por el deseo que poner punto y final a una poesía social y neorrealista que creían agotada e injustificada a finales de los años sesenta -Jaime Siles, por su parte, defiende que, más que contra la poesía social, estos poetas reaccionaron "contra la noción dominante de un discurso que, desde 1939, y salvo muy ppocas excepciones, apenas [...] había experimentado variación" (9)-, para iniciar la búsqueda de nuevos caminos poéticos: neobarroquismo, anticonfesionalismo, etc.

La ruptura que anunciaba la segunda antología de Batlló a la que Lanz se refiere ${ }^{3}$ se convirtió en el elemento protagonista de Nueve novísimos poetas españoles, "de importación italiana" (Bou y Pittarello 9) 4 . La editorial barcelonesa de Carlos Barral, Barral Editores, que editó a los novísimos, ya había dejado huella en la historiografía literaria española diez años antes con la publicación de la antología Veinte años de poesía española (1939-1959), realizada también por el propio Castellet. Para su -

3 Guillermo Carnero, uno de los elegidos por Castellet, defiende que la ruptura que el crítico catalán anuncia en Nueve novísimos ya "la habían preparado los poetas que nosotros hemos llamado independientes en el período de 1950-1965; en ellos se produce, o bien una actitud crítica hacia las pretensiones de la poesía social, o bien una reivindicación de la primacía del lenguaje poético por encima de cualesquiera exigencias contenidistas" (Lanz 69).

4 "Castellet había tomado el título de la antología que en 1961 había lanzado de la mano de A. Giuliani un neovanguardismo en Italia: I novissimi" (Lanz 20). Aun así, según Prieto de Paula, el término "ya había sido empleado antes [en 1968] en una antología en homenaje a Aleixandre con motivo de su setenta aniversario [...], donde se recogen poemas de generaciones sucesivas, desde la del 27 a la -así denominada- 'Generación novísima"” (86). 
antología el padre de los novísimos eligió a nueve poetas, alguno de ellos sin obra publicada ${ }^{5}$, y seleccionó diez poemas de cada uno, precedidos de una poética escrita por los propios autores. Castellet empleó un criterio natalicio para agruparlos en dos secciones: "los seniors", formados por Manuel Vázquez Montalbán, Antonio Martínez Sarrión y José María Álvarez, y "la coqueluche", término que no hace justicia a la producción poética de algunos de sus miembros, a pesar de que la denominación sea "cariñosa" "; los agrupados aquí son Félix de Azúa, Pere - por entonces Pedro- Gimferrer, Vicente Molina Foix, Guillermo Carnero, Ana María Moix y Leopoldo María Panero. La selección concreta de estos nombres fue una de las causantes del nacimiento de aquel "cerco de desprecio o de ira" en torno a la antología al que se refería Félix Grande:

Se enfadaron los nuevos poetas que se creían con derecho a estar incluidos por ser tan rupturistas y vanguardistas como los seleccionados (el caso más aparatoso fue el de José Miguel Ullán); se enfadaron los poetas jóvenes que querían continuar la poesía social desde presupuestos menos simplistas que los habituales; incluso algún poeta de la generación anterior, como el siempre ponderado Ángel González, pareció perder ostensiblemente los nervios en prosa y verso (García Martín VII).

Algunos de los poetas del primer grupo a los que se refiere José Luis García Marín, que "ocuparon un espacio 'a la sombra de' o 'frente a' la antología de Castellet", fueron Francisco J. Carrillo, Antonio Carvajal, Antonio Colinas, Francisco Ferrer Lerín, Aníbal Núñez, Juan Luis Panero, Jaime Siles, Jenaro Talens y Jorge Urrutia, entre otros, según la propuesta de José Francisco Ruiz Casanova (XVI).

Las críticas hacia la propuesta castelletiana empezaron a salir a la luz incluso antes de la publicación de la antología7. Ejemplo de ello es la

5 Sobre el proceso de elección de los novísimos, véase Lanz 117-120.

6 De la siguiente manera define Castellet a este grupo: "denominación cariñosa dada por alguno de sus mayores a la irrupción de un grupo de jóvenes tan irritantes como una enfermedad infantil y tan provocativos e insolentes, en poesía, como puede serlo un adolescente con ganas de divertirse a costa de un grupo de venerables ancianas, además encabezados por la precocidad insultante de Pedro Gimferrer" (28).

7 Sobre ello, escribe irónicamente el barcelonés: "Castellet, de un colectivo de 10.000 poetas jóvenes, o los que fueran, seleccionaba nueve, con lo que sembraba 9.991 agravios, multiplicados por los agravios compartidos de los amigos, amigas, novios, novias, 
carta a la revista Triunfo firmada por Julián Chamorro Gay y Aníbal Núñez, donde sus autores exponen "la sospecha de que tras esta actitud renovadora no existe más que una poesía metropolitana de evasión y divertimentos formalistas" (257); una nueva poesía, en definitiva, formada por "amigos de Centralia" que excluye cualquier voz que no pertenezca al ámbito Madrid-Barcelona, como se señala en una enardecida reseña a Nueve novísimos bajo la firma de C. F. (268). El otro principal motivo de las críticas fue el propio Castellet $^{8}$, de quien se dijo que era "un fenómeno, fundamentalmente extraliterario, de la literatura española contemporánea" (Meliá 264), así como que su persona era mucho más importante y conocida que la de los poetas antologados (Conte 259). Indudablemente, como asegura Jenaro Talens, "si el nombre del antólogo no hubiera sido el que es ni la casa editora la que fue, posiblemente el carácter canónico que ha acompañado al libro durante todos estos años no habría existido" (30). Es un hecho, pues, afirmar que Nueve novísimos poetas españoles se convirtió en el canon de la poesía del $68^{9}$ y que,

amantes, maridos, esposas, madres, padres, tíos, tías, abuelos, abuelas de los 9.991 no escogidos" ("Sobre los 'novísimos'...” 423).

8 Vázquez Montalbán entendió perfectamente cuál era el entramado que había detrás de la antología, pero no por ello pudo tolerar el ensañamiento que gran parte de la crítica tuvo con Castellet: "Minutos después de habernos leído Castellet el prólogo de los Nueve novísimos dichosos, bajaba la escalera de su casa con Félix de Azúa (otro de los implicados) y comentábamos: en el libro, el que quedaba mejor de todos es el propio Castellet. 'Nos es relativamente infiel', comentó Azúa con profundísima comprensión. El público no lo ha entendido así, salvo excepciones, y Castellet ha quedado tan 'novísimo' como nosotros nueve y me atrevería a decir que más insultado incluso. Porque a un servidor le han llamado chismorrero y a Gimferrer 'Celia Gámez', pero a Castellet le han llamado ignorante e infiel. Son cargas de profundidad. Son insultos serios. Científicos dirían, de no temer devaluar una palabra que tantos respectos merece" ("Castellet o la ética..." 260). ${ }^{9}$ La importancia canónica de los novísimos fue tal que en 1986 Luis Antonio de Villena tituló a una antología que pretendía aunar el panorama de la joven poesía española de aquella época Postnovísimos. Por su parte, José Luis Cano en Lírica española de hoy, antología publicada en 1975, identifica a "los más jóvenes poetas" del momento exclusivamente con los novísimos, concretamente Vázquez Montalbán, Gimferrer y Carnero (14 y 15), olvidándose por completo de cualquier otro autor del 68 excluido por Castellet en el libro. Asimismo, cuenta Lanz que tras cinco años de la publicación de Nueve novísimos se produjo un intento fallido de llevar a cabo una segunda edición de la obra, "ampliando la selección de poemas y reduciendo la de poetas" (101 y 102). 
en palabras de Jaime Siles, aceleró el proceso de su repercusión "al poner en venta un fruto aún no maduro" (11).

Pero con el canon llegó el error, una de las mayores confusiones de la historiografía literaria del XX causada en gran medida por los odios que despertó Nueve novísimos: la identificación de poesía novísima como poesía culturalista. El culturalismo, corriente cuyos rasgos fueron advertidos inicialmente por José Hierro en los años sesenta (López, 2010: 46), consiste, según la definición de Prieto de Paula, "en la utilización en el poema de referencias - abundantes, no consabidas y explícitas - de la historia cultural, instaladas en el territorio de lo imaginario mítico, tanto si son constitutivas esenciales del poema como si son sólo un anexo circunstancial del mismo", siempre que estas referencias no aumenten su implicitud y se hagan irreconocibles "una vez que se han diluido en la riqueza formativa del autor" (174); en él se insertan de manera clara un primer Gimferrer y, sobre todo, la obra de Carnero, quedando lejos de esta nueva expresión estética el resto de poetas novísimos. El culturalismo fue entonces considerado como el sinónimo indiscutible de poeta novísimo, y, por consiguiente, el rechazo hacia la poesía culturalista fue en aumento con el paso de los años, siendo uno de las principales estéticas a superar por la denominada "poesía de la experiencia" que irrumpió en España en los años ochenta. Se puede apreciar perfectamente esta confusión -y este rechazo hacia el culturalismo-, en parte intencionada si se atiende al largo catálogo de vituperios que recibieron los novísimos, en una carta que Jaime Gil de Biedma escribió a Luis García Montero en julio de 1985, quien llegará a afirmar años más tarde que el culturalismo es un "circo ornamental" (208), donde el poeta barcelonés da sus opiniones al joven poeta de Granada sobre los autores antologados por Castellet:

En cuanto grupo, siempre he pensado de ellos que confundían demasiado a menudo creación de actualidad literaria con la creación literaria. Gimferrer es un poeta excelente, lo mismo en castellano que en catalán, y su poesía me divierte aunque no estoy seguro de que me interese mucho. De Carnero me interesa lo que ha estado intentando hacer a partir de Variaciones sobre un tema de la Bruyère -me interesa más la tentativa que lo conseguido- y hay un poema de Blablapoldo Panero, "Deseo de ser piel roja" (muy en la línea de Poeta en Nueva York), que me gustó mucho cuando lo leí. Lo que conozco del resto -que no es mucho, ciertamente- me parece más bien pobre. Es curioso que la obra de un grupo tan programáticamente esteticista y culturalista ofrezca tan poco interés en cuanto a materia artística, innovaciones y técnica literaria -a 
ese respecto, uno puede prescindir de ellos bastante tranquilamente. Félix de Azúa, por ejemplo, me ha parecido siempre un versificador aficionado. Los cambios fueron más temáticos que formales (Gil de Biedma 422 y 423).

No obstante, esta identificación equívoca fue más allá, y al poco tiempo a los poetas novísimos se les empezó a denominar poetas venecianos, término peyorativo y un tano desafortunado que acuñó Eladio Cabañero y que se encargó de difundir Francisco Umbral (Barnatán 16); peyorativo por recordar el desafecto existente hacia el culturalismo y desafortunado por su intención unificadora de todos los poetas del 68, ahora todos novísimos, pues el hecho de que tres de aquellos autores escribieran un poema inspirado o dedicado a la ciudad de Venecia ("Oda a Venecia ante el mar de los teatro", de Gimferrer; "Muerte en Venecia", de Carnero, y "Oración en Venecia", de Marcos-Ricardo Barnatán) hizo que la aparición de dicha ciudad se consagrara como una de las características indiscutibles de la poesía sesentayochista. Comenzó a asumirse la idea de que todos los poetas novísimos escribían sobre Venecia y esto no era bien acogido en el panorama poético de las España de los sesen$\mathrm{ta}^{10}$. Debido a esta -absurda siempre- máxima, que reducía a otras muchas propuestas estéticas y formales que enriquecieron la poesía después del medio siglo "a un problema de Venecias en ruinas o de Príncipes contemplando el deterioro de las cornamusas sobre el cadáver incorrupto de sus antepasados" (26), la obra de un número elevado de autores, como es el de caso de Vázquez Montalbán, dejó de interesar no solo a los lectores y a los estudiosos de la poesía española de aquel tiempo, sino también a las generaciones poéticas futuras. A esta falta de memoria también se la debe relacionar con que algunos de los novísimos, como el propio barcelonés o Félix de Azúa, durante el desarrollo de sus respectivas trayectorias literarias abordaron otros géneros además de la poesía, y gran parte de la crítica inmediatamente los clasificó antes como $-$

10 El propio Vázquez Montalbán fue tachado de poeta veneciano al incluir el gentilicio en uno de sus versos: "Muy pocos se tomaron la molestia de deslindar las radicalmente diferentes poéticas que coexistían en aquel libro, y hasta que un notable tratadista me clasificó como poeta veneciano, junto a Gimferrer, por el simple hecho de que yo en un poema, en un solo poema, hablaba de algo más o menos veneciano. Decía que un verdugo, y me estaba refiriendo a Franco, se miraba en 'las venecianas aguas de un espejo roto'. Consto, pues, como poeta veneciano en una antología poética para estudiantes universitarios. Peores cosas me han dicho" (“Sobre los 'novísimos'...” 423-424). 
narradores que como poemas. En este aspecto, el caso de Vázquez Montalbán es notorio, cosa que siempre le molestó, como demuestra en un artículo publicado en El País el 3 de diciembre de 1985, ya citado anteriormente:

[...] no hace mucho en las páginas de este diario un, por otra parte, excelente escritor publicaba el réquiem 1.000 o 2.000 de Los novísimos y se esforzaba en demostrar que casi todos los poetas seleccionados por Castellet ya no éramos poetas, éramos novelistas, o críticos, o profesores, o jurados de premios literarios. Le falla la memoria o el archivo al ilustre articulista; en casi todos los nueve casos, y en lo que a mí respecta, cuando Castellet me metió en su selección nacional sólo había publicado dos libros de poemas y en la actualidad he publicado cinco, el último y excelente, en 1982, con el título de Praga. Cinco libros son muchos libros, demasiados diría yo, y creo merecer la etiqueta de poeta que no he dejado en mal lugar la opción de Castellet: es decir, ser uno de los 10.000 mejores poetas españoles a fines de la década de los sesenta ("Sobre los 'Novísimos' ..." 425).

El escritor barcelonés, el mayor de los "seniors" de Castellet, publicó en Nueve novísimos poetas españoles diez textos: "Conchita Piquer", "IX [Nunca desayunaré en Tiffany...]", "XI [Rodajas de limón...]", "XII [Qué poco me cuesta creerlo...]" y "XV [Olvidable la muerte de todos, tú...]", que ya habían sido recogidos en la 1. a ed. de Una educación sentimental [1967], primer poemario publicado de Vázquez Montalbán y el único en aquella fecha; "Suave es la noche” y “¡No corras, papá!”, inéditos hasta su inclusión en Nueve novísimos, aunque un mes después de la aparición de la antología fueron recogidos en la 2. ${ }^{\text {a }}$ ed. ampliada de Una educación sentimental; "Poema publicitario...", incluido también en la obra montalbaniana Manifiesto subnormal [1970], y "Arte poética", inédito hasta la fecha, e "¿Yvonne de Carlo? ¿Yvonne de Carlo?... ¡Ah! ¡Yvonne de Carlo!", "poema especialmente escrito para Nueve novisimos", tal y como lo señala Vázquez Montalbán en Memoria y deseo, recopilación de su obra poética entre 1963 y 1990 (137), aunque es muy posible que "Arte poética" asimismo hubiera sido concebido inicialmente para formar parte de la antología. El también novísimo José María Álvarez ha declarado que, además de que no existía una estética común entre los nueve, "los poemas que le enviamos ni siquiera representaban lo más considerable del carácter de cada uno, ya que Castellet nos solicitó 'lo más innovador', lo más escandaloso, aunque se trata, como en 
muchos casos sucedió, de poemas a medio elaborar o experimentos que, afortunadamente, serían abandonados o pronto olvidados" (Fernández 150). Bien podrían estar dentro de estos poemas "escandalosos" a los que se refiere Álvarez "Arte poética" e "¿Yvonne de Carlo?...", textos ambos cargados de una gran ironía, más el primero que el segundo, también latente en la poética que Vázquez Montalbán escribió expresamente para Nueve novísimos, aunque, asegura Lanz, las nueve poéticas de los novísimos

tenían un cierto tono irónico, manifiesto en una voz naif en algunos casos, en otros en una voz distanciada, que servía para presentar una serie de ideas de un modo irónicamente ingenuo, falsamente frívolo, que encarnaba el discurso aparentemente desideologizador, el distanciamiento de una estética de compromiso ideológico, expuesto en su contenido. En cierto modo, hacían suyo el tono ("medio en serio, medio en clave divertida") en que discurría el discurso teórico del texto prologal (132).

Quizás esta ironía pretendía ocultar o disfrazar los planteamientos expuestos por Castellet en las cinco secciones del prólogo que encabeza la antología, un texto teórico donde el lector puede encontrar cierta inestabilidad en los planteamientos teóricos del crítico catalán, "precariedad -afirma Talens- que el antólogo honestamente subraya y explicita" (30). Cuatro son los puntos que Castellet propone en su prólogo como comunes para alcanzar la homogeneidad generacional:

1) "despreocupación hacia las formas tradicionales" (41);

2) "introducción de elementos exóticos, artificiosidad", destacando el gusto por todo aquello ajeno a lo español y la notable influencia de la cultura proveniente de los mass media (42);

3) "escritura automática, técnicas elípticas, de sincopación y de 'collage"” (41 y 42), donde habría que situar uno de los dos tipos de "cogitus interruptus" que protagonizaron, según Castellet, algunos poetas de la antología, como Vázquez Montalbán y Martínez Sarrión, esto es, "la voluntariedad de ruptura con una lógica sociolingüística que traduce los esquemas organizativos de una sociedad irracional y represiva" (34) -en esta "libertad expresiva" generada por dicha ruptura, Ángel Otero-Blanco ve además una intención de "desarticular el sistema referencial y represivo de la dictadura y trascender los oxidados moldes sociales y existenciales de la literatura de posguerra" (60)-, lo cual se relaciona directamente en 
la obra montalbaniana con los planteamientos de la denominada escritura subnormal cultivada por el barcelonés, tan presentes en su poética de Nueve novísimos (García García 57); asimismo, cabe destacar el empleo de la técnica del collage: en el caso de Vázquez Montalbán representaría desde una visión general "el mestizaje cultural que él siempre defendió, reflejado sobre todo por la convivencia de géneros literarios en un mismo texto" (57), un collage, más allá de lo formal, que nada tenía que ver con los cultivados por sus compañeros de antología:

Tampoco mi collage cultural es equiparable al de otros poetas de los ya viejos novísimos [...] El collage de Gimferrer es fundamentalmente iconográfico, aséptico, como lo había sido en Pound o en Eliot. En Panero era la denuncia del caos, la declaración de la imposibilidad de ordenar ese puñado de imágenes rotas sobre las que inevitablemente cae la noche. En mi caso era la confesión de mi propia arqueología sentimental, de las ruinas que hay en uno mismo, de las ruinas que hay en todo lo nuevo, en todo lo contemporáneo (Vázquez Montalbán, “¿Dónde están los rapsodas...” 8);

y 4) "tensiones internas del grupo" (Castellet 43 y 44). Estas tensiones a las que se refiere Castellet versan sobre el tratamiento del fenómeno camp: lo camp, o el "gusto camp", como lo denomina su creadora Susan Sontag, "es una nueva manera de mirar al mundo como fenómeno estético" o, en otras palabras, lo camp supone una nueva propuesta de visión artística que pretende la democratización de todos los elementos, situando así en un mismo nivel aquellos elementos pertenecientes a la "alta cultura" y a aquellos pertenecientes a la cultura de masas; lo camp es, en definitiva, "la equivalencia de todos los objetos" (357 y 372).

Volviendo a las tensiones castelletianas, lo que defiende el crítico es la existencia de una doble interpretación de lo camp: algunos autores asumen este fenómeno "como posibilidad de preconizar una poesía que arranque de la cultura popular", y otros lo reciben "como asunción snob, aristocratizante, de los mitos populares" (Castellet 44) -es preciso señalar que para Castellet la base de la ruptura novísima reside en el tratamiento de numerosos elementos provenientes de los mass media, los cuales se han convertido en una nueva cultura popular asumida por toda una generación (23 y 24)-. Vázquez Montalbán es situado por su antólogo en el primer grupo, pero este se equivoca, ya que la finalidad del empleo de la 
cultura popular es otra en el caso del barcelonés; así lo explica en el prólogo a la edición moderna de Crónica sentimental de España:

No me movía a mí la pulsión camp, teorizada entonces por Susan Sontag, [...] puesto que yo no cultivaba el pop con un propósito vanguardista o lúdico, sino como un acto de reafirmación de mi propia conciencia de origen y proyecto personal y colectivo. Yo utilizaba los materiales de la cultura popular con el mismo respeto sacro con el que un poeta culto podía utilizar los referentes adquiridos en la biblioteca de su padre, su abuelo, hasta su tatarabuelo (22).

Además, leyendo el planteamiento de Sontag sobre lo camp, sus palabras rápidamente revelan una escasa visión de futuro para esta "nueva manera de mirar el mundo", dadas sus pretensiones rebeldes mal argumentadas y su falta de coherencia en no pocos de sus puntos ${ }^{11}$. Lo camp se redujo a una moda pasajera de finales de los años sesenta, y así lo señala en un artículo Vázquez Montalbán, empleando su particular ironía, tan mordaz e indigesta a veces, que tanto caracteriza su estilo:

hay otro sector, muy próximo al de los 'snobs', que espera la novedad que le conviene como quien espera el autobús que ha de llevarle a los más exactos paraísos terrestres. De momento, este sector se ha subido a un autobús que el 'snob' ya contempla con desdén, allá en la lejanía, pero que todavía no ha llegado a su destino.

Perdonen tan largo prolegómeno. Ese autobús es el camp. La cultura camp ("De la kulturkampf..." 34).

Para escritores como el barcelonés, lo camp "se confundió con el empeño de recuperar la memoria que nos urgía a los escritores que habíamos llegado a la adultez" (“¿Dónde están los rapsodas...” 8). La democratización cultural que tan presente está en la obra montabaniana, y que guarda una estrecha relación con el collage,

más que mostrar sencillamente que una canción de Conchita Piquer, como bien puede ser Tatuaje, posee la misma relevancia cultural que los versos de La tierra baldía, de Eliot -esto sería estar de acuerdo con Sontag-, pretende reivindicar y devolver al pueblo esa cultural popular de la que se había apo-

11 Por ejemplo: "Lo camp es arte que quiere ser serio pero que sin embargo no puede ser tomado enteramente en serio porque es 'demasiado"” (Sontag 365). 
derado el franquismo, así como ser la expresión clara y coherente del mestizaje cultural de su propia generación (García García 69).

Y este fin para Vázquez Montalbán no es otro que la recuperación de su memoria particular, donde convive, en palabras de él mismo, "la cultura convencional que aprendí en los libros apellidados y en la Universidad" con la cultura pop proveniente de los medios de comunicación de masas (“¿Dónde están los rapsodas...” 7).

Aunque para Castellet, como ya se ha explicado, la presencia del camp de Sontag en las propuestas poéticas de los novísimos o la recurrente presencia de elementos alejados de la tradición española en sus textos eran algunos de los puntos de confluencia entre sus nueve autores seleccionados, para Vázquez Montalbán esta característica unitaria respondía, entre otras, a "la reacción contra la poesía social más grosera" (Lanz 25). No solo había que superar la popular idea poetizada por Gabriel Celaya de que "la poesía es un arma cargada de futuro" -pensaba el barcelonés-, sino que era necesario rectificar el significado del adjetivo, cuya interpretación estaba completamente alejada de su verdadera definición ${ }^{12}$; así lo explica en la poética -"Rápidas notas sobre la llamada "poesía social"'- que escribió para la antología Poesía social, de Leopoldo de Luis, en la que fue incluido en su 2. ${ }^{a}$ ed. en 1969:

La expresión poesía social es una convención cultural falsa.

[...] Social es todo tipo de poesía y todo tipo de comunicación cultural. Hay poesía muy social: las letras que ha cantado Antonio Machín, por ejemplo, o las de Conchita Piquer, Juanita Reina, Valderrama, etc. Hay poesía un poco menos social: la de Rafael de León, José Carlos de Luna, etc. Hay poesía un poco social: la de Celaya, Blas de Otero, José Agustín Goytisolo, García Nieto, López Anglada, la mía, etc. Es más social la poesía más sociable, que llega, objetivamente a más gente. Es menos social la menos sociable, la que sólo leemos unos 2.500 españoles.

[...] Ocurre que entre todos hemos hecho el juego a "la poesía social" y la hemos escrito como si fuera a provocar vastos movimientos de masas, como

12 Resulta interesante recordar aquí la afirmación de uno de los personajes de la novela La soledad del manager [1977], de Vázquez Montalbán: en un determinado momento, el detective Pepe Carvalho se encuentra con un bedel que está leyendo La Realidad y el Deseo, de Luis Cernuda, y tras descubrir que dicho sujeto es poeta y después de unas breves palabras, el bedel afirma: "La poesía no es ni social ni tangerina, o es poesía o no es nada" (64). 
si la poesía estuviera dirigida a la inmensa mayoría, como si la poesía fuera material estratégico convencional de primera clase en la lucha frente a la contradicción de primer plano o la contradicción fundamental. [...] la disposición moral a hacer "poesía social" estaba cargada de idealismo y por lo tanto de romanticismo formal.

[...] ¿Qué puede hacer un poema del mismísimo Blas de Otero, con una circulación de mil o dos mil ejemplares, frente a programaciones de TV como el viaje del Apolo VIII, que llegan a 700 u 800 millones de seres?

[...] Esta lucidez da una mayor libertad de creación, posibilita el hecho experimental, carga de realismo a la propia poesía, permite superar el ridiculismo: ismo en el que se incurre cuando el poeta confunde su estilográfica con un proyectil dirigido o su subjetividad con la energía nuclear.

[...] Tras unos años en que la "poesía social" se autojustificaba porque había una identidad entre la intención de la protesta y su formalización, en la actualidad, la significación de "poesía social" se corresponde a la función de un modesto tirachinas (De Luis 535-537).

Asimismo, Vázquez Montalbán encuentra otros puntos de confluencia entre él y el resto de sus compañeros novísimos, aunque son características que perfectamente podrían ampliar sus fronteras y aplicarse a la poesía sesentayochista en general -véase la consonancia que tienen las siguientes ideas con los cuatro puntos sobre el panorama literario del 68 sugeridos al principio de este estudio:

Porque algo nos unía. Haber asimilado la relativización del sujeto poético, ya practicada por los Valente, Biedma, Barral, Ferrater, González, Crespo, Goytisolo y compañía ${ }^{13}$; haber comprendido la relativización de la función social-histórica de la literatura; valorar la exigencia de lo literario y rechazar

13 Andrew Debicki entiende la distancia que estos poetas — no todos - cogen con respecto al yo confesional como un primer acercamiento o un primer síntoma del culturalismo: "Si la generación anterior seguía preocupada, a pesar de su escepticismo, por el 'yo' en la realidad circundante, el escepticismo más fundamental de los 'novísimos' les lleva a considerar el 'yo' como a menudo aislado de tal realidad, y relacionado más bien con su lenguaje y con la ficción artística que éste pueda crear. En último término, llegan a percibir la realidad que les llega a través del arte como de igual importancia que la que se les entrega anecdóticamente. Su así llamado 'culturalismo' estriba, en efecto, no en un deseo de deslumbrar al lector con alusiones, sino en la creencia de que una nueva experiencia artística se crea a menudo a base de una obra de arte previa" (15). Quizá Debicki vuelve a caer en el error al considerar que todo el 68 fue culturalista, pues el tratamiento del yo por parte de estos autores fue mucho más complejo y variado; véase, para ello, Prieto de Paula 329-368. 
la justificación de las buenas intenciones ideológicas; partir de un nivel de información cultural superior en relación a las promociones de la posguerra, en parte gracias al esfuerzo hecho por las promociones de la posguerra (“Sobre los 'novísimos'..." 424).

En cambio, si se presta atención a algunas entrevistas realizadas al barcelonés, las diferencias entre los novísimos, desde su punto de vista, son más notables que sus puntos en común, en la línea de lo que ya se ha comentado sobre la asunción de la técnica del collage: "Pocas cosas compartíamos radicalmente, y si alguien se toma la molestia de releernos comprobará que cada poeta es un caso" (424), sentencia. En primer lugar, están los orígenes sociales: "Esos orígenes sociales han marcado mi talante y mi manera de apropiarme del patrimonio y de adquirir un código. Yo soy un mestizo cultual real y casi todos los demás novísimos habían adoptado un mestizaje mitómano y lúdico", confiesa Vázquez Montalbán, remarcando que esta cuestión se aprecia en las poéticas que acompañaban a cada autor en la antología (Rico, "Entrevista..." 22). Y en segundo lugar, la proximidad a los poetas del medio siglo. Opina Vázquez Montalbán que algunos de sus compañeros, como Gimferrer, "han dado el salto sobre lo más inmediato para llegar a la generación del 27 o a poetas extranjeros, como Octavio Paz o Wallace Stevens. Han ido a buscar sus mentores culturales fuera y no en casa, porque los que estaban a su alcance les parecieron mediocres. Yo no he prescindido de esa generación inmediata, pero también he buscado modelos extranjeros" (Campbell 159).

De estos poetas, el barcelonés se siente más ligado a "Jaime Gil de Biedma y Gabriel Ferrater, a tres poemas de Carlos Barral, al primer libro de Goytisolo, a algunos poemas de Valente" (Batlló 363 y 364), pero tampoco desecha a las promociones poéticas anteriores, destacando especialmente a Antonio Machado, Blas de Otero, "cierto Celaya" y José Hierro (Rico, "Entrevista..." 22), quienes han influido notablemente en su producción poética, así como autores extranjeros como Cesare Pavese o su admirado T. S. Eliot (Tyras 13), autor omnipresente tanto en su poesía como en su obra en prosa.

Con respecto a los poetas del medio siglo, Manuel Rico establece un paralelismo entre Vázquez Montalbán y estos autores, considerando al barcelonés como un claro heredero de las claves poéticas de los escritores que lo precedieron. "El enorme valor de la experiencia íntima y 
colectiva como suministradora de emociones susceptibles de convertirse en poesía"; la presencia de "la realidad diaria, las ciudades - la ciudad, la amistad, el amor"; la representación literaria de "la experiencia de lo cotidiano", y la consideración del poema como vía de conocimiento y como unidad crítica, son algunos de los rasgos de la poesía del medio siglo que Rico resalta dentro de la poesía de Vázquez Montalbán (Memoria, deseo y compasión 43-46), lo cual lleva a considerar, en palabras de Santiago Martínez, a la producción poética del barcelonés "como obra de transición entre la generación del medio siglo y el posterior aire renovador de los novísimos" (V), o al menos el enlace inicial con dicha generación (Otero-Blanco 59), que también se podría aplicar al resto de los "seniors", negando de tal modo esa ruptura absoluta con la poesía anterior que Castellet expuso en su prólogo (Lanz 67).

Es un hecho claro que si Manuel Vázquez Montalbán no hubiera formado parte de Nueve novísimos poetas españoles, la presencia de su obra poética en la literatura española del s. XX hubiera pasado por completo desapercibida. Aun así, el ser uno de los elegidos por Castellet no hizo que su poesía fuera tan recordada como la de alguno de sus compañeros, como Gimferrer o Carnero; no fueron pocas las antologías posteriores a Nueve novísimos que excluyeron al barcelonés de sus índices ${ }^{14}$. El caso montalbaniano, entonces, no coincidiría con la creencia de José Olivio Jiménez de que lo único que perdurará de estos autores, "como más firme y permanente, es su poesía de madurez" (1); como es bien sabido, el lector común solo recuerda de su poesía algunos poemas de Una educación sentimental, especialmente aquellos incluidos en Nueve novísimos, y alguno más por motivos más bien anécdoticos que literarios, como es el caso del texto "El cartero ha traído el Bangkok Post...", de Pero el viajero que huye [1990] (Cruz Ruiz 289). Talens defiende que la estrategia canonizadora de la antología castelletiana desembocó en que muchas de las propuestas de escritura fueran sustituidas, simplemente, por nombres propios, y poetas como Vázquez Montalbán y Leopoldo María Panero, cuyos "planteamientos eran los más radicales, ideológica y políticamente hablando", fueron paulatinamente siendo olvidados al no corresponderse con los gustos dominantes " $\mathrm{y}$, en consecuencia, más asimilables por la crítica establecida" (31); incluso se podría interpretar que

\footnotetext{
14 Véase Rico, “Introducción” 19.
} 
la falta de memoria hacia estos poetas fue síntoma de su no correspondencia con las propuestas culturalistas, más recordadas por los ataques que recibió de muchos frentes de la crítica que por su calidad literaria.

Pero, ¿podríamos llamar a Vázquez Montalbán novísimo? Es más: ¿qué implica ser un poeta novísimo? Desde un punto de vista estético y teórico, difícilmente se podría afirmar que los nueve poetas que Castellet lanzó con su antología tuvieran un potente nexo común para constituir una promoción poética definida. Es cierto que la etiqueta de novísimo sirve para designar a estos nueve autores, pero el problema recae en que dicha designación ha eclipsado a un gran número de voces contemporáneas - por no decir coetáneas- que sí que estaban siendo, a la par que los novísimos, agentes del cambio de la poesía española de finales de los años sesenta; los nueve mil novecientos noventa y escritores novísimos los llamaría Vázquez Montalbán (La literatura... 154). Como ya se ha demostrado en las páginas anteriores, Nueve novísimos se convirtió en el canon de los poetas del 68, y ello trajo consecuencias muy perjuiciosas para las nuevas propuestas literarias que se estaban gestando, pues enseguida toda la poesía que se escribió antes, después y durante la antología castelletiana ya solo podía ser para la mayor parte de los lectores, una poesía novísima, esto es, culturalista y, aún peor, veneciana. ¿Cuál fue entonces el verdadero y definitivo fantasma que recorría España en 1971: Nueve novísimos o su circunstancia posterior? Definitivamente, las constantes críticas hacia la antología, venidas de diversos círculos culturales, catapultaron su fama, su nombre y su consolidación dentro del canon, así como la figura en sí de Castellet, cuyo papel en el panorama literario de la segunda mitad del s. XX no era precisamente secundario. Por tanto, ¿existe una serie de características concretas para determinar si un poeta es o no es novísimo? El ejemplo de Vázquez Montalbán es revelador: poca similitud literaria tenía él con sus compañeros novísimos, similitud que sí se podría encontrar, por ejemplo, entre Gimferrer y Carnero, pero que no existe como tal entre los nueve antologados, lejos ya de las polémicas y las constantes críticas. Nueve novísimos poetas españoles fue una publicación puntual que se aprovechó de un momento concreto de cambio literario y que, por razones absolutamente extraliterarias, se convirtió en norma más que en ideario.

Sería, así pues, una afirmación liviana considerar que Manuel Vázquez Montalbán fue propiamente un poeta novísimo; es innegable su parti- 
cipación en la antología de Castellet, lo cual le ha otorgado el derecho a recibir ese calificativo, pero el problema reside, como se ha intentado demostrar en las páginas anteriores, en la propia denominación de "novísimo", que responde antes a cuestiones vinculadas con la cronología de la historiografía literaria que a la denominación de una generación poética o un grupo de escritores que comparten entre sí un ideario literario, donde, como ya se ha señalado, apenas funciona. Vázquez Montalbán en su obra Un polaco en la corte del Rey Juan Carlos recuerda un encuentro con el poeta José-Miguel Ullán, excluido de la antología, en una fiesta que organizó Miguel García Sánchez durante la Feria del Libro de Madrid de 1995, donde propone una conclusión muy coherente de lo que fueron en realidad los poetas novísimos para él: "me lanzo a recordar con Ullán lo que pudo haber sido y no fue en torno a Los nueve novísimos, que pudieron ser incluso once o ciento uno" (77).

Muchísimas voces poéticas que empezaron a surgir a lo largo de los años sesenta, algunas más relacionas con otras, sufrieron de un modo u otro la aparición y la designación de la antología de Castellet, que marcó un antes y un después en la poesía española de la segunda mitad del XX. De la noche a la mañana, todos recibieron la etiqueta de novísimos, y unos huyeron de ella, otros la obviaron, y hubo algunos, como Manuel Vázquez Montalbán, que siguieron escribiendo una poesía hasta el final de sus días completamente al margen de todas las corrientes en las que se disgregó el 68; una poesía, aunque aislada, ante todo personal y comprometida con la mirada artística de su creador.

\section{Bibliografía}

Barnatán, Marcos-Ricardo. "La polémica de Venecia". Ínsula. Revista de Letras y Ciencias Humanas 508 (1989): 15 y 16. Impreso.

Batlló, José. Antología de la nueva poesía española. Madrid: Ciencia Nueva, El Bardo, 1968. Impreso.

Bou, Enric, y Pittarello, Elide. "Introducción: las claves de la Transición”. Enric Bou y Elide Pittarello, eds. (En)claves de la Transición. Una visión de los Novísimos. Prosa, poesía, ensayo. Madrid / Frankfurt am Main: Iberoamericana-Vervuert, La Casa de la Riqueza, 2009. 7-37. Impreso.

Campbell, Federico. Infame turba. Barcelona: Lumen, 1971. Impreso. 
Cano, José Luis, ed. Lírica española de hoy. Antología. Madrid: Cátedra, Letras Hispánicas, 1998 (14ª ed.). Impreso.

Castellet, J. M., ed. Nueve novísimos poetas españoles, Barcelona: Península, 2010. Impreso.

Chamorro Gay, Julián, y Núñez, Aníbal. "Cultura e industria". Castellet, J. M., ed. Nueve novísimos poetas españoles. Barcelona: Península, 2010. 257 y 258. Impreso.

C. F. “¡Oh, no!”. Castellet, J. M., ed. Nueve novísimos poetas españoles. Barcelona: Península, 2010. 268. Impreso.

Conte, Rafael. "J. M. Castellet o la crítica como provocación". Castellet, J. M., ed. Nueve novísimos poetas españoles. Barcelona: Península, 2010. 258-261. Impreso.

Cruz Ruiz, Juan. Egos revueltos. Una memoria personal de la vida literaria. Barcelona: Tusquets, Fábula, 2013. Impreso.

De Luis, Leopoldo, ed. Poesía social española contemporánea. Antología (1939-1968). Ed. Fanny Rubio y Jorge Urrutia. Madrid: Biblioteca Nueva, Clásicos de Biblioteca Nueva, 2010 ( $2^{\mathrm{a}}$ ed.). Impreso.

Debicki, Andrew. "La poesía postmoderna de los novísimos: una nueva postura ante la realidad y el arte". Ínsula. Revista de Letras y Ciencias Humanas 505 (1989): 15 y 16. Impreso.

Fernández, J. Benito. El Contorno del Abismo. Vida y leyenda de Leopoldo María Panero. Barcelona: Tusquets Editores, Fábula, 2006. Impreso.

García Berrio, Antonio. "El imaginario cultural en la estética de los 'Novísimos"”. Ínsula. Revista de Letras y Ciencias Humanas 508 (1989): 13-15. Impreso.

García García, Sergio. "Las canciones de Conchita Piquer y otras alusiones subculturales en la primera poesía de Manuel Vázquez Montalbán”. Cuadernos de Aleph 8 (2016): 56-71. Digital.

García Martín, José Luis. "Una antología necesaria". Anthropos. Boletín de Información y Documentación 110-111 (1990): VII y VIII. Impreso.

García Montero, Luis. Las inquietudes bárbaras. Barcelona: Anagrama, Argumentos, 2008. Impreso.

Gil de Biedma, Jaime. El argumento de la obra. Correspondencia (19511989). Ed. Andreu Jaume. Barcelona: Lumen, 2010. Impreso. 
Grande, Félix. "Poetas novísimos, vieja confusión”. Castellet, J. M., ed. Nueve novísimos poetas españoles. Barcelona: Península, 2010. 283285. Impreso.

Jiménez, José Olivio. "Variedad y riqueza de una estética brillante". Ínsula. Revista de Letras y Ciencias Humanas 505 (1989): 1 y 2. Impreso.

Lanz, Juan José. Nuevos y novísimos poetas en la estela del 68. Sevilla: Renacimiento, Iluminaciones, 2011. Impreso.

López, Ignacio Javier. "Introducción”. Carnero, Guillermo. Dibujo de la muerte. Obra poética (1966-1990). Ed. Ignacio Javier López. Madrid: Cátedra, Letras Hispánicas, 2010 (2ª ed. rev.). 11-80. Impreso.

Martínez, Santiago. "La poesía de los 'seniors': las voces que no se apagan. Manuel Vázquez Montalbán, Antonio Martínez Sarrión y José María Álvarez". Anthropos. Boletín de Información y Documentación 112 (1990): V-XII. Impreso.

Meliá. "Castellet y los novísimos". Castellet, J. M., ed. Nueve novísimos poetas españoles. Barcelona: Península, 2010. 264-266. Impreso.

Otero-Blaco, Ángel. "Poesía novísima y social en Manuel Vázquez Montalbán”. Enric Bou y Elide Pittarello, eds. (En)claves de la Transición. Una visión de los Novísimos. Prosa, poesía, ensayo. Madrid / Frankfurt am Main: Iberoamericana-Vervuert, La Casa de la Riqueza, 2009. 57-77. Impreso.

Prieto de Paula, Ángel L. Musa del 68. Claves de una generación poética. Madrid: Ediciones Hiperión, 1996. Impreso.

Rico, Manuel. "Entrevista a Manuel Vázquez Montalbán”. Ínsula. Revista de Letras y Ciencias Humanas 605 (1997): 21-24. Impreso.

---. Memoria, deseo y compasión. Una aproximación a la poesía de Manuel Vázquez Montalbán. Barcelona: Mondadori, 2001. Impreso.

---. "Introducción". Vázquez Montalbán, Manuel. Una educación sentimental. Praga. Ed. Manuel Rico. Madrid: Cátedra, Letras Hispánicas, 2001. 11-66. Impreso.

Ruiz Casanova, José Francisco. “¿La última generación poética española?". Anthropos. Boletín de Información y Documentación 110-111 (1990): XIV-XVII. Impreso.

Siles, Jaime. "Los novísimos: la tradición como ruptura, la ruptura como tradición". Ínsula. Revista de Letras y Ciencias Humanas 505 (1989): 9-11. Impreso. 
Sontag, Susan. Contra la interpretación. Trad. Horacio Vázquez Rial. Madrid: Alfaguara, 1996. Impreso.

Talens, Jenaro. "De poesía y su(b)versión (Reflexiones desde la escritura denotada 'Leopoldo María Panero')". Panero, Leopoldo María. Agujero llamado Nevermore (Selección poética, 1968-1999). Ed. Jenaro Talens. Madrid: Cátedra, Letras Hispánicas, 2014 (4ª ed.). 7-51. Impreso.

Tyras, Georges. Geometrías de la memoria. Conversaciones con Manuel Vázquez Montalbán. Granada: Zoela, 2003. Impreso.

Vázquez Montalbán, Manuel. "De la kulturkampf a la culturcamp". Triunfo 39420 Dic.1969: 32-35. Impreso.

---. “¿Dónde están los rapsodas de antaño?”. Coplas a la muerte de mi tía Daniela. Barcelona: Editorial Laia, Laia Literatura, 1984. 7-10. Impreso.

---. Un polaco en la corte del Rey Juan Carlos. Madrid: Alfaguara, Alfaguara Extra, 1996 ( $3^{a}$ ed.). Impreso.

---. Memoria y deseo. Obra poética 1963-1990. Barcelona: Mondadori, Biblioteca Vázquez Montalbán, 2000. Impreso.

---. La literatura en la construcción de la ciudad democrática. Barcelona: Mondadori, Biblioteca Vázquez Montalbán, 2001. Impreso.

---. Crónica sentimental de España. Barcelona: Debolsillo, 2003 (2. ${ }^{\mathrm{a}}$ ed.). Impreso.

---. La soledad del manager. Madrid: Diario Público, Colección Vázquez Montalbán, 2006. Impreso.

---. "Sobre los 'novísimos' y sus postrimerías". Obra periodística. Volumen II: Del humor al desencanto (1974-1986). Ed. Francesc Salgado. Barcelona: Debate 2011. 423-425. Impreso.

---. "Castellet o la ética de la infidelidad". Obra periodística. Volumen I: La construcción del columnista (1960-1973). Ed. Francesc Salgado. Barcelona: Debate 2016. 260-266. Impreso. 